\title{
A IMPORTÂNCIA DOS SABERES NECESSÁRIOS A PRÁTICA DOCENTE
}

Alexsandra dos Santos Jesus ${ }^{1}$ Mariluse Santana dos Santos ${ }^{2}$

\section{RESUMO}

Esse artigo tem como objetivo discutir sobre a importância dos saberes necessários a prática docente. Ministrar aula não é uma tarefa fácil para quem ensina e principalmente para aquele que aprende. E são muitos os saberes e fazeres necessários na profissão docente para a garantia das aprendizagens e desenvolvimento das habilidades dos alunos. É no espaço escolar que o professor constrói seus saberes referentes ao ensino por meio da realização das suas atividades práticas. Ou seja, é nesse ambiente que produz saberes e fazeres próprios, se tornando autor da sua própria prática pedagógica. Quanto ao procedimento metodológico optou-se pela pesquisa bibliográfica que é obrigatória em qualquer modalidade de investigação científica. Conclui-se que com as mudanças ocorridas na sociedade, a prática docente sempre está em constantes transformações.

Palavras Chaves: Prática docente. Saberes. Escola. Professor. Aluno

\section{ABSTRACT}

This article aims to discuss the importance of the necessary knowledge for teaching practice. Teaching classes is not an easy task for those who teach and especially for those who learn. And there is a lot of knowledge and practice necessary in the teaching profession to guarantee the learning and development of the students' skills. It is in the school space that the teacher builds his knowledge regarding teaching through the realization of his practical activities. In other words, it is in this environment that it produces its own knowledge and practices, becoming the author of its own pedagogical practice. As for the methodological procedures, bibliographic research was chosen, which is mandatory in any type of scientific investigation. It concludes with the changes that have taken place in society, the teaching practice is always in constant transformations.

Keywords: Teaching practice. Knowledge. School. Teacher. Student

\footnotetext{
${ }^{1}$ Mestra em Ciências da Educação pela FICS; Especialista em Gestão Escolar com ênfase em Coordenação Pedagógica pela Montenegro; Especialista em psicopedagogia Escolar e Clinica pela FAVIX; Especialista em Alfabetização e Letramento pela FBB; Licenciada em pedagogia pela FAMEC; Docente na Prefeitura de Camaçari/BA.Email:alexsandradsj@gmail.com.

${ }^{2}$ Mestra em Ciências da Educação pela FICS; Especialista em Arte Educação pela Faculdade Afonso Claudio; Especialista em Alfabetização e Letramento pela Como Educare; Licenciada em Normal Superior e Pedagogia pela UNIJORGE; Docente na Prefeitura de Camaçari/BA.

Email:marilusesantos@yahoo.com.br
} 


\section{Introdução}

Conhecimentos inerentes à prática do docente, são adquiridos através das experiências práticas e das teorias da Educação. O conhecimento teórico é de suma importância para conhecer as diversas concepções que podem contribuir com iniciativas e atitudes para entender a dinâmica do dia a dia da sala de aula e proporcionar saberes e fazeres para o desenvolvimento de novas práticas pedagógicas. Nesse sentido percebe-se que:

Os saberes teóricos propositivos se articulam, pois, aos saberes da prática, ao mesmo tempo ressignificando-os e sendo por eles ressignificados. O papel da teoria é oferecer aos professores perspectivas de análises para compreender os contextos históricos, sociais, culturais, organizacionais, e de si mesmos como profissionais, nos quais se dá sua atividade docente, para neles intervir, transformando-os. (PIMENTA, 2005, p.26)

Os saberes teóricos aliados aos saberes da prática contribuem para que o professor desenvolva um conhecimento formado da relação teórica e prática promovendo uma reflexão de suas ações que serão construídas gradativamente. Relacionar teoria e prática proporciona a aquisição de novas concepções e exemplos de diversas práticas pedagógicas que auxiliam na aprendizagem dos alunos. Ou, seja ele adquire novos saberes para a sus prática docente.

A construção da formação do professor ocorre antes e no processo de constituição docente. Sua formação depende das teorias estudadas e das práticas vivenciadas no cotidiano da escola, é fundamental que o profissional da educação tenha como desafio procurar especificar e entender as teorias, identificando as suas práticas e criando circunstâncias das concepções teóricas. Haja mudanças de entendimento ação comportamento e desempenho seu papel na dinâmica educacional (ALARCÃO, 2005).

A formação do professor é fundamental, mas só ela não dá conta de preparar o profissional da educação para exercer a sua função. Ao se apropriar de novos saberes o professor obtém ganhos das teorias que auxiliam as compreensões sobre a aprendizagem e a selecionar as mais importantes maneiras de desenvolver seu trabalho com qualidade, facilitando o exercício da reflexão e a crítica sobre sua própria prática docente.

Faz-se necessário que os professores tenham a oportunidade de estar pesquisando, participando de cursos, oficinas, formações etc que promovam 
discussões e troca de experiências sobre novas ou aperfeiçoadas estratégias de ensino. Para ter uma prática pedagógica de qualidade é necessário investir ir nas pesquisas sobre teorias em uma busca diária dos saberes necessários a prática docente

\section{Os Saberes Necessários Para Prática Docente}

Os saberes docentes têm sido um dos temas mais pesquisados nas duas últimas décadas, percebem-se cada vez mais pessoas interessadas em realizar pesquisas a respeito desse tema de suma importância, para o desenvolvimento da formação profissional do docente, pois "ao contrário de outros ofícios que desenvolveram um corpus de saberes, o ensino tarda a refletir sobre si mesmo" (GAUTHIER, 1998, p.20).

O autor acima citado ainda acrescenta que, nas pesquisas sobre o ensino, deparam-se como dois obstáculos que há muito tempo estão inseridos na pedagogia, sendo eles: um ofício sem saberes e de saberes sem ofício. De forma mais explicita pode-se explicar que:

\footnotetext{
O primeiro obstáculo é em relação a ação do professor referente as atividades realizadas sem revelar os saberes específicos. $O$ ensino existe desde a antiguidade e sabemos tão pouco sobre ele, e ainda convivemos com o princípio de que ensinar é simplesmente transmitir conhecimentos, conhecer o conteúdo, ter cultura, talento, bom senso, intuição, e ter experiência. O segundo obstáculo está relacionado aos saberes sem ofício, são os conhecimentos elaborados nas instituições acadêmicas, onde muitos deles não atendem as reais demandas que interferem no ensino, necessitando de intervenções (Ibi., p. 20-25).
}

O melhor que se pode fazer é enfrentar o desafio da profissionalização docente, procurando evitar esses dois erros: o ofício sem saberes e os saberes sem ofício. É possível perceber a existência de conhecimentos peculiares ao ensino e um ofício feito de saberes.

Citando como exemplo o professor alfabetizador atualmente nesse cenário, ele precisa munir-se de diversos saberes além dos específicos de alfabetizador, e fazer valer seu dever de proporcionar a aprendizagem da leitura e da escrita das crianças, através da compreensão do letramento. Durante todo o processo da formação do professor, é construído muitos saberes que serão reconstruídos a partir de vivências e experiências no dia a dia da escola, contribuindo com o desenvolvimento de sua identidade profissional (BRITO, 2007). 
As ações contínuas da alfabetização e letramento, mesmo tendo cada uma sua especificidade, tornam-se inseparáveis na prática pedagógica alfabetizadora; no processo de condução dos alfabetizandos; e no desenvolvimento das habilidades de leitura e escrita, tornando significativas através da inserção no mundo do letramento por meio dos usos sociais da língua escrita.

Ao vivenciar os saberes na prática, o professor reestrutura seu saber e fazer profissional, diante das exigências e necessidades apresentadas na ação. Nesse sentido, os saberes diversos que o professor constrói durante todos os seus anos de experiências, reafirmam sua prática pedagógica, transformando em saberes que estarão sempre em continuação e modificação (TARDIF, 2002).

A prática docente é entendida como uma atividade social, porque é uma ação individual de cada professor de acordo com o seu trabalho e as atividades na aula, proporcionado a elaboração de saberes e fazeres através da reflexão, sobre a ação em sala de aula e possibilitando a troca de experiências entre os profissionais, por isso, Dessa forma "a prática é um processo constante de estudo, de reflexão, de discussão, de experimentação conjunta e dialeticamente com o grupo de professores" (IBERNON, 2005, p.4).

As aprendizagens adquiridas pelos professores se transformam em saberes por meio dos fundamentos teóricos, contribuindo para a prática pedagógica onde as experiências de suas histórias de professores vivenciadas nos seus trabalhos, auxiliará cada dia a reflexão da ação na sala de aula. Nesse sentido, é fundamental destacar que os saberes dos docentes em atuação sejam mobilizados e utilizados por eles no âmbito de suas tarefas cotidianas, pois, "o que se propõe a partir desse postulado é considerar os professores como sujeitos que possuem saberes específicos ao seu ofício e ao seu trabalho" (TARDIF, 2003, p.113).

Pode-se afirmar que todos os saberes fundados na prática do professor, só têm grande valor ao transformar-se em conhecimentos que venham a afirmar 0 trabalho docente. Saberes plurais adquiridos de muitas áreas descreve-se como saber proveniente dos fundamentos teóricos e práticos, em aprendizagens das experiências e trocas com os colegas docentes, no dia a dia da sala de aula, do conhecimento individual de cada aluno e de todo o ambiente escolar.

Existem na atividade docente quatro tipos de saberes que são: os saberes da experiência; os saberes da formação profissional (das ciências da educação e da ideologia pedagógica); os saberes disciplinares; e os saberes curriculares. Os 
saberes são diversos e procedente dos estudos de todo o processo de formação do professor, sendo estes adquiridos por meio das experiências e conhecimentos específicos da sua área e profissão. Os saberes docentes como mais aprofundamento, são constituídos pelos:

Saberes dos pontos disciplinar, curricular, das ciências da educação, da tradição pedagógica, experiencial e saber da ação pedagógica. Afirmando ainda que o ensino é a mobilização de vários saberes que formam uma espécie de reservatório no qual o professor se abastece para responder as exigências específicas de sua situação concreta de ensino (GAUTHIER 1998, p 27).

Com passar do tempo, o professor vai obtendo cada vez mais conhecimentos, experiências e saberes sobre sua profissão e especificamente de todo o âmbito da escola, que foi armazenado ao longo de sua formação profissional, podendo recorrer a sua bagagem sempre que necessário. Sabendo que esses não são algo que se adquire simplesmente na bagagem para utilizar em algumas situações, é necessário que o professor conheça muito sobre a escola, pois:

\begin{abstract}
O professor possui um conjunto de saberes a respeito da escola que é desconhecido pela maioria dos cidadãos comuns e pelos membros das outras profissões. É um saber profissional específico, que não está diretamente relacionado com a ação pedagógica, mas serve de pano de fundo tanto para ele quanto para os outros membros de sua categoria socializados da mesma maneira. Esse tipo de saber permeia a maneira de 0 professor existir profissionalmente (GAUTHIER et al, 2006, p.31).
\end{abstract}

Os saberes adquiridos no processo da formação inicial, sendo eles os saberes da própria profissão e das disciplinas, vão se modificando a cada dia no trabalho da sala de aula com a construção e a contribuição dos saberes curricular; da experiência; dos saberes científico e demais saberes obtidos em todo o seu processo de formação. Nesse sentido, tanto o processo educativo quanto os saberes pertencentes, são complexos e pode revelar cinco categorias de saberes: o saber atitudinal, o saber crítico contextual, os saberes específicos, o saber pedagógico e o saber didático curricular (SAVIANI, 1996).

É necessário que esses saberes sejam incluídos no desenvolvimento da formação dos professores, podendo assim, oferecer conhecimentos que proporcionem competência sobre eles e que todo docente precisa entendê-los. Nesse sentido, o professor precisa prover-se de saberes para o exercício da docência levando em consideração que "em lugar dos saberes determinarem a formação do educador, é a educação que determina os saberes que entram na formação do educador" (Ibid., p. 145). 
Professores munidos dos saberes múltiplos enfrentam os desafios de conduzir em harmonia a organização da sua turma e do todo o desenvolvimento do seu trabalho, para alcançar os objetivos antes planejados, pois, "esse saber diversificado dos professores sancionado é o saber docente composto de vários saberes oriundos de fontes diferentes e produzidos em contextos institucionais e profissionais variados" (TARDIF e GAUTHIER,1996, p.11).

Para que isso aconteça, faz-se necessário os professores selecionarem os saberes adequados e apropriados para o ensino. E diante dessa concepção vale salientar que educador é aquele que educa, o qual, consequentemente, precisa saber educar, precisa aprender, precisa ser formado, precisa ser educado para ser educador, precisa dominar os saberes implicados na ação de educar (Ibidem.).

O ensino é um trabalho mundial e realizado há muitos anos, e continua até os dias atuais como imprescindível para a humanidade. Porém, diante desse trabalho histórico pode-se afirmar que:

\footnotetext{
Mal conseguimos identificar os atos do professor que, na sala de aula, tem influência concreta sobre aprendizagem dos alunos, e estamos apenas começando a compreender como se dá a interação entre educador e educandos (GAUTHIER et al, 1998, p.17).
}

A falta de pesquisas da prática do professor no dia a dia da sala de aula traz dificuldades na identificação dos saberes necessários para este saber ensinar, para "o que acontece quando o professor ensina e o que ele faz exatamente para instruir e educar as crianças" (Ibid., p.17-18).

Diante dessas inquietações a partir das duas últimas décadas, alguns autores iniciam o desenvolvimento de investigações a respeito da prática do professor, pois "a profissão docente é uma pratica educativa, é uma forma de intervir na realidade social, no caso mediante a educação" (PIMENTA; ANASTASIOU, 2008, p.178). A educação sendo uma prática social compreendida na relação teoria e prática, "é nosso dever como educadores, a busca de condições necessárias a sua realização" (VEIGA, 1989, p. 16).

A medida em novos conhecimentos e concepções eram revelados a partir das investigações sobre a prática do professor novas teorias foram surgindo e foi-se percebendo a grande importância para a divulgação do imenso repertório de conhecimentos específicos de ensino. Esses conhecimentos contribuíram para 
esclarecer sobre o ato de ensinar minimizando impasses para perceber e observar os saberes necessários para este saber ensinar.

\section{Considerações}

No processo ao longo de sua profissão, os professores buscam apropriaremse de saberes relacionado aos objetivos, métodos, discursos e conteúdo. O saber docente abrange a prática e as experiências do dia a dia, além da formação inicial.

Na contemporaneidade, o avanço tecnológico e seus recursos pertencentes a nova cultura social, que está conectada aos fatos de todo o planeta em tempo real, traz para o professor desafios de se aperfeiçoar, de participar de formação continuada buscando sempre estar atualizado, aberto a aprender e a ensinar ao mesmo tempo. Ou seja, estar atento às necessidades e aos interesses apresentados pelos alunos.

Através do saber profissional, o professor deve desenvolver conhecimentos próprios e ser reconhecido por constituir esse saber, que é originário das experiências da prática diária. O saber profissional dos docentes é formado por vários saberes provenientes das experiências do fazer. Para saber enfrentar situações difíceis no cotidiano escolar devem-se recorrer às várias concepções teóricas, estratégias, habilidades e metodologias buscando minimizar os problemas

O professor precisa desenvolver outro olhar direcionado para a preparação dos alunos, para atuarem nesse novo mundo, enfrentando vagas de empregos deixando de lado o cuidado em formar estes, em relação a saberem viver exercendo valores e ética e a cidadania. Para a concretização da profissão docente pautada na atuação educativa, é fundamental o professor buscar libertar se do modelo e das referências tradicionais e aderir aos conhecimentos que contribuam com 0 desenvolvimento da crítica e a reflexão, considerando o debate como a base para a atuação docente.

Os conhecimentos que foram aqui abordados, neste artigo é dedicada a todos os profissionais da educação e áreas afins, que de alguma forma expressam desejo de conhecer e ou contribuir para melhoria desse fenômeno na luta por essa causa. Esse artigo não é um fim em si e nem apresenta resultados conclusivos a respeito do tema, mas estará aberto as novas discussões e pesquisas. 
Referências:

ALARCÃO,I. Formação reflexiva de professores: estratégias de supervisão. Porto: Porto Editora, 2005.

BRITO, A. E .Sobre a formação e a prática pedagógica: o saber, o saber-ser e o saber fazer no exercício profissional. In: MENDES SOBRINHO, J. A. C.(Org.). Formação e prática pedagógica: diferentes contextos de análises.Teresina: EDUFPI, 2007.

GAUTHIER, C. Por uma teoria da pedagogia: pesquisas contemporâneas sobre o saber docente - Coleção Fronteiras da Educação. ljui: Ed. UNIJUİ, 1998.

GAUTHIER, C. et al. Por uma teoria da pedagogia: pesquisas contemporâneas sobre o saber docente. 2. ed. ljuí:Editora Unijuí, 2006.

IMBERNÓN, F. Formação docente e profissional: formar-se para a mudança e a incerteza. 5. ed. São Paulo, SP: Cortez, 2005.

PIMENTA, S. G. O estágio na formação de professores: unidade teórica e prática? 3. ed. São Paulo: Cortez, 2005.

SAVIANI, D. Os saberes implicados na formação do educador. In: BICUDO, M. A.; SILVA JUNIOR, C. (Orgs.). Formação do educador: dever do Estado, tarefa da Universidade. São Paulo: Unesp, 1996.

TARDIF, M; GAUTHIER, C. O saber profissional dos professores: fundamentos e epistemologia. In: Seminário de Pesquisa Sobre o Saber Docente..Fortaleza: UFCE, 1996.

TARDIF, M. Saberes Docentes e Formação Profissional. 2 ed. Petrópolis: Vozes, 2002.

TARDIF, M. Saberes docentes e formação profissional. 3 ed. Rio de Janeiro: Vozes, 2003.

VEIGA, I.P A. A prática pedagógica do professor de didática. Campinas: Papirus, 1989. 